\title{
Analysis of Structural State of 60/40 Brass Cartridge Case (BCC) after Being Exposed to High Pressure and Temperature of Firing
}

\author{
Abdalla Saif Eldin Mohammed \\ Giad Group, Khartoum, Sudan \\ Email: abdosaf1@yahoo.com
}

How to cite this paper: Mohammed, A.S.E. (2019) Analysis of Structural State of 60/40 Brass Cartridge Case (BCC) after Being Exposed to High Pressure and Temperature of Firing. Open Journal of Applied Sciences, 9, 710-724.

https://doi.org/10.4236/ojapps.2019.99058

Received: April 15, 2019

Accepted: September 21, 2019

Published: September 24, 2019

Copyright $\odot 2019$ by author(s) and Scientific Research Publishing Inc. This work is licensed under the Creative Commons Attribution International License (CC BY 4.0).

http://creativecommons.org/licenses/by/4.0/

\begin{abstract}
This research presents an experimental and analytical study of the structural state of the 60/40 brass cartridge case, (BCC) after being fired. The oral section of the $\mathrm{BCC}$ has the function of confining the gases of firing by expanding against the chamber and sealing the gases. Firing conditions, namely, high pressure and temperature, $3000 \mathrm{bar}$ and $2727^{\circ} \mathrm{C}$, respectively, affect performance properties of the (BCC). These are confining and crack strengths. Experimental study was done on the oral section to address these effects on the structural and mechanical properties of this brass. This alloy is a $60 \%$ copper $(\mathrm{Cu})$ and $40 \%$ zinc $(\mathrm{Zn})$ alloy and has a two-phase structure, alpha, $(\alpha)$ and beta, $(\beta)$. Using "before and after" comparison approach; performance properties were tested in cartridge cases prepared before and after firing. These properties are hardness, tensile strength, micro-structural and chemical composition. Comparing the tests' results, after firing demonstrated considerable degrading in performance properties, micro-structural disorder and a remarkable deficiency in the zinc element in the brass structure. This deficiency affects the percentage of beta phase in the alloy which governs the strength of the brass. According to the required properties before firing, it was found that after firing, the brass cartridge case is not qualified for reloading.
\end{abstract}

\section{Keywords}

Structural State, Brass Cartridge Case (BCC), Deficiency of Zinc, Reloading

\section{Introduction}

The brass $60 / 40$ is a copper alloy composed of $60 \%$ copper and $40 \%$ zinc with miner impurities. It has a two-phase structure, alpha, $(\alpha)$ and beta, $(\beta)$. In case of alloy with concentration of $\mathrm{Zn}$ from $36 \%$ to $40 \%$, the $\beta$ phase exists after the soi- 
dification, and it enhances and increases the mechanical properties with good cold forming. This can be illustrated in Figure 1 and Figure 2 [1].

Cartridge case is commonly manufactured from this alloy for its strength and formability. It has the disadvantage of being defective after firing and not qualified for reloading. Atypical BCC is shown in Figure 3.

\section{Oral Section of the Case}

The main problem since 150 years ago, behind scraping brass cartridge cases, was the defects occurred in the brass material after firing [2]. Those defects were faced when improving a technology for cartridge case renewal process by Dr. Jeno Sipos. In their former case of renewal process, there were cracks in the renewed artillery brass cases. In a short storage time, the renewed cases exhibit cracks and hence reloading these cases which were dangerous in firing, for crew and weapon as well. Experiments were made on 85 spent and renewed brass cases; 50 - $60 \mathrm{~mm}$ long cracks were found in the mouth and neck of the cases. Metallurgical test was made on case samples and revealed an interecrystalline feature crack which implies stress corrosion cracking as an effect of stresses caused by firing which can be seen in Figure 4 .

The study proved that during artillery activity the case suffered deformation which can cause internal stress. Although the temperature is high, about $2626^{\circ} \mathrm{C}$, has no remarkable effect on the case. This is because the time for shelling is very short, about $7.522 \mathrm{~ms}$ and the temperature needed for recrystallization is 0.4 melting temperature of brass which is $290^{\circ} \mathrm{C}$. The case temperature was measured immediately after shelling and found to be between $90^{\circ} \mathrm{C}$ to $140^{\circ} \mathrm{C}$, which lower than recrystallization temperature. They concluded that the case suffered

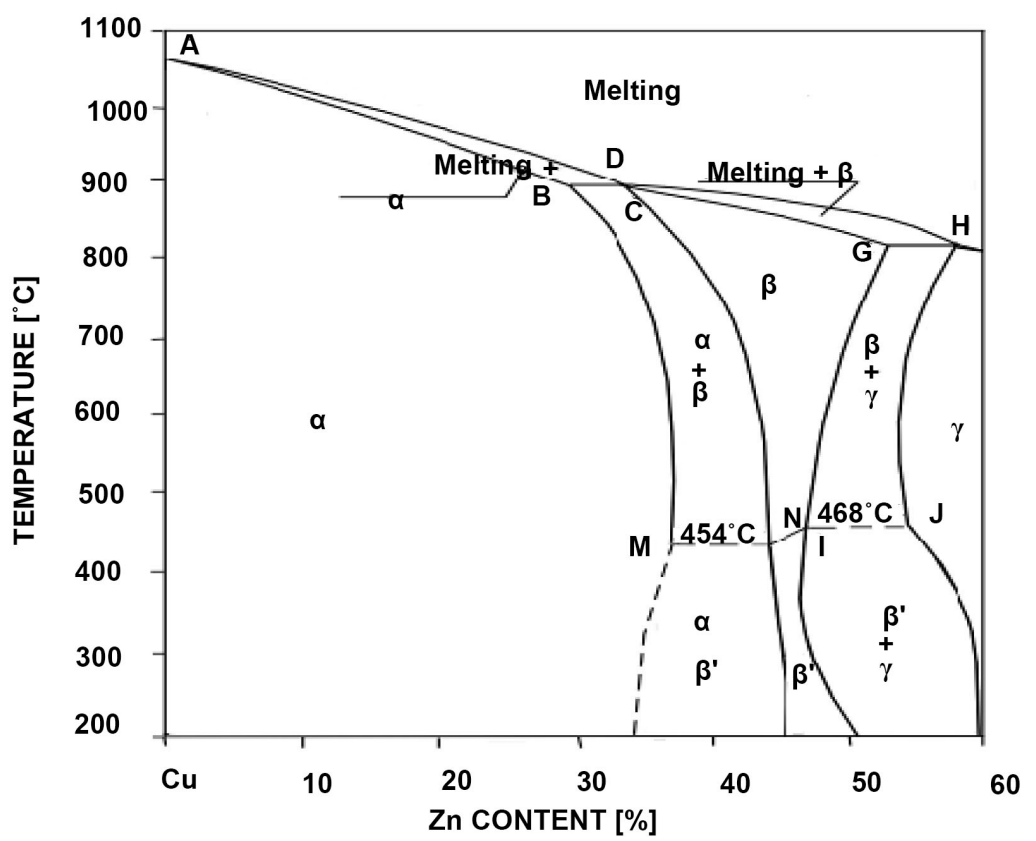

Figure 1. Binary diagram copper-zinc [1]. 


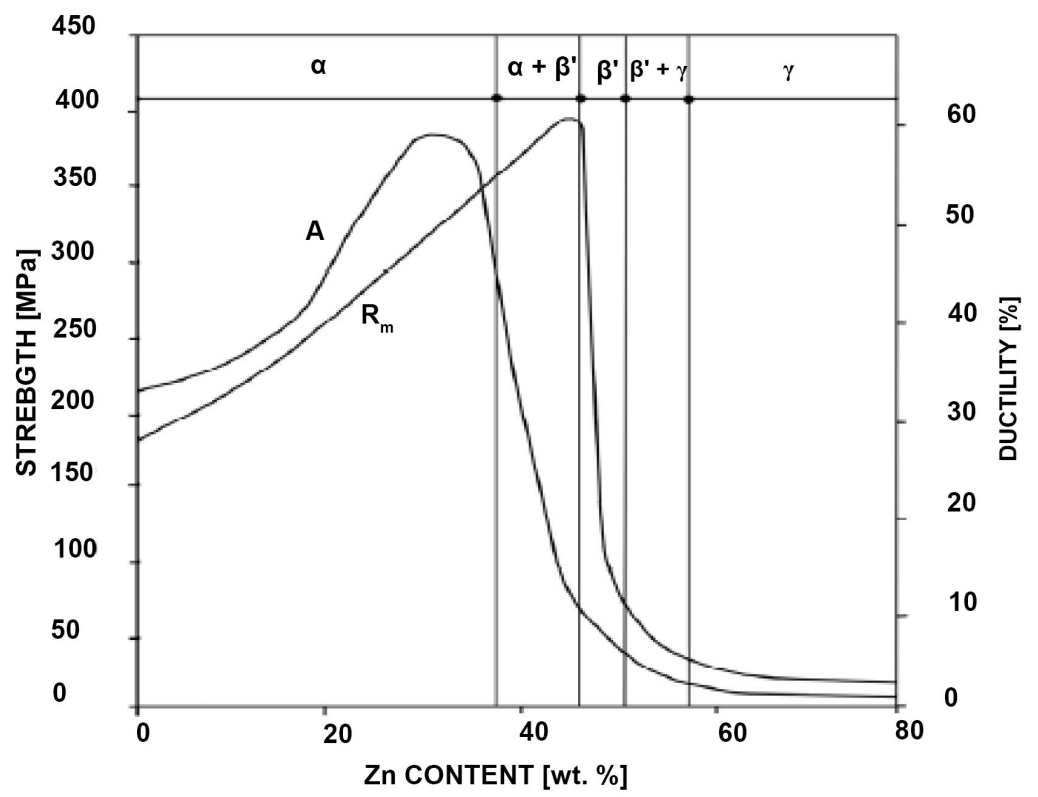

Figure 2. Influence of the $\mathrm{Zn}$ content to the brass mechanical properties [1].

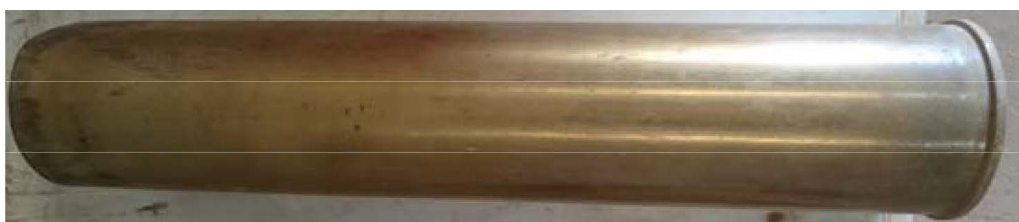

Figure 3. Typical fired brass cartridge case.
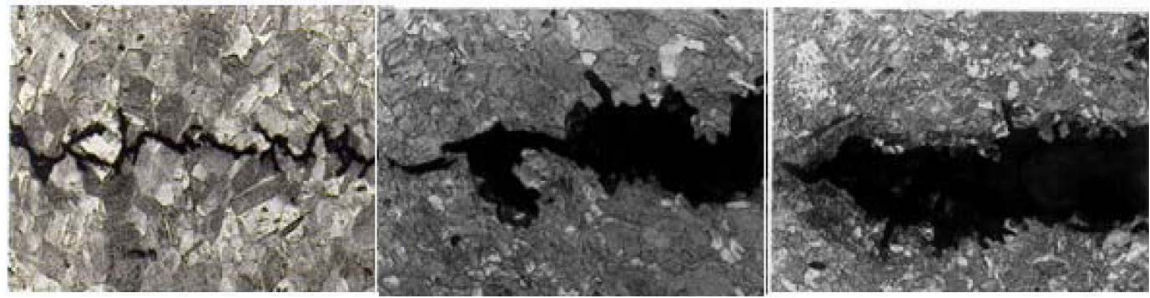

Figure 4. Intercrystalline feature cracks. Amplification $=250 x$; Etched in $10 \%$ ammonium persulphate [2].

only from deformation and not temperature [2]. Later studies introduced the combustible cartridge case (CCC), which offer specific advantages over the conventionally metallic brass case. The CCCs are made of cellulose fibers with suitable explosives to ensure debris-free combustion inside the gun barrel. Nevertheless, the presence of explosives in CCC, causes increased vulnerability to cook-off. This phenomenon was studied and addressed by the researchers, R.K. Syal and P.S. Narr, in 1992 and found only $50 \%$ of protecting methods gave better results [3].

To compromise between the advantages of metallic and combustible cartridge cases, study was made by the same researchers discussing the design of Brass Obturator of Combustible Cartridge Case for 105 mm Tank Gun Ammunition. 
They concluded their study by cutting the defective cartridge case part and replaced by a combustible cartridge part due to deformation occurred in the oral section of the cartridge case [4].

This paper showed that the deformation and cracks were not the only deterioration occurs on the case cartridge, but there is a considerable strength reduction and micro-structural change in terms of phases structure (alloying elements) and grain distribution, size and orientation.

Those changes were addressed using experimental study of tensile strength, microstructural and chemical analysis states before and after firing of brass cartridge case. When comparing the results obtained from before and after states, there are recognizable effects on the performance of the cartridge case.

\section{Methodology}

\section{Materials and Equipments}

Based on "before and after" comparison approach, two groups of samples were prepared, the first group made before firing, (unfired) 60/40 brass cartridge cases with standard mechanical properties for firing; and the second group comprises cartridge cases with the same performance properties after firing, (fired) cases and collected from the range test.

According to American Society for Testing and Materials ASTM standard, the sample groups were further divided and prepared into four subgroups to perform hardness test, tensile strength, microstructure and chemical composition tests. The samples were shown attached with every test method bellow.

\section{Methods}

\subsection{Hardness Test}

Using TH600 Brinell hardness device, Figure 5, twenty pieces from fired and unfired cartridge cases were tested for Brinell hardness (HB). The brinell hardness testing is suitable for such material (brass) and thickness (1-3 mm). The device was set up with $125 \mathrm{~kg}$ force, $2.5 \mathrm{~mm}$ ball indenter diameter and 15 seconds for loading time. After loading is finished, the average indentations diameters are obtained and then the corresponding $\mathrm{HB}$ value is calculated using the tables attached to the device.

\subsection{Tensile Strength Test}

Tensile strength test was performed using a computerized tensile tester and samples prepared as shown in Figures 6(a)-(d). After entering the sample dimensions (width, thickness and cross-section area), the samples were pulled till breaking and the corresponding loads, the tensile strength and graphical representation of the test were directly given by the machine.

\subsection{Metallographic Test}

Metallographic test was made to investigate the microstructure of samples using 


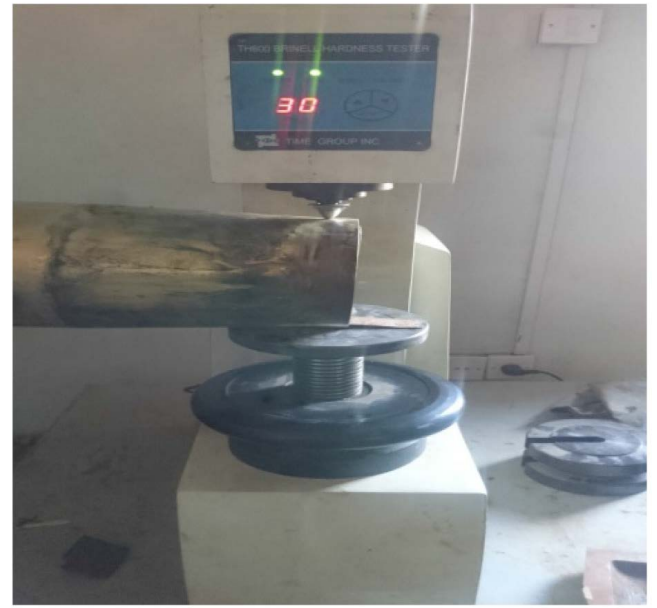

Figure 5. TH600 Brinell hardness test device with the sample mounted.

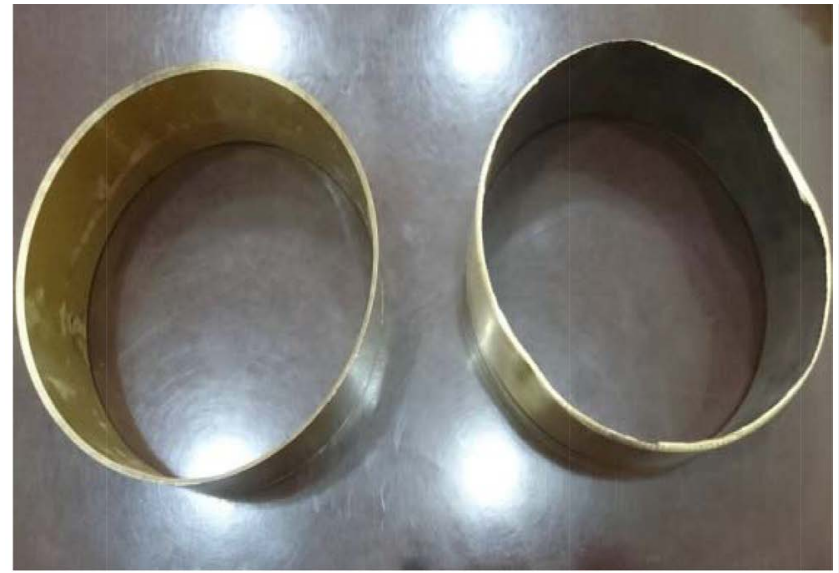

(a)
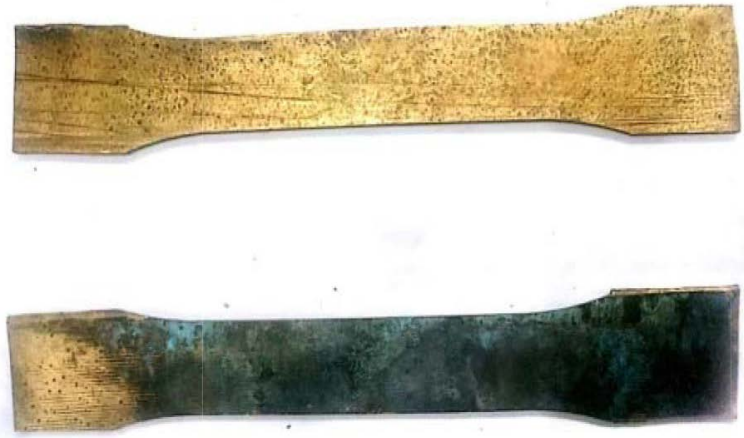

(c)
Shape of body sample of machanical performance M1:2

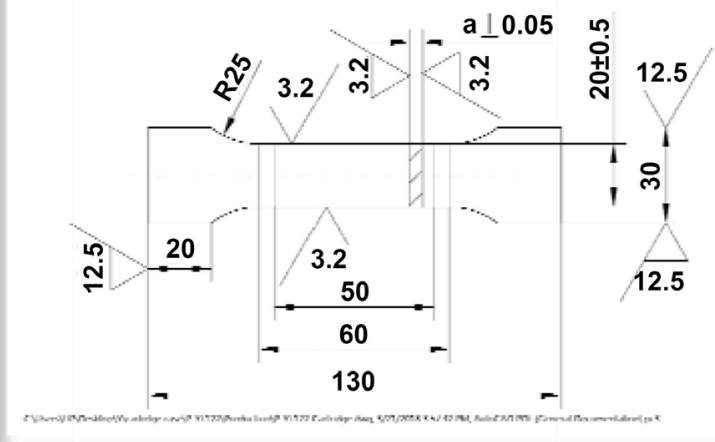

(b)

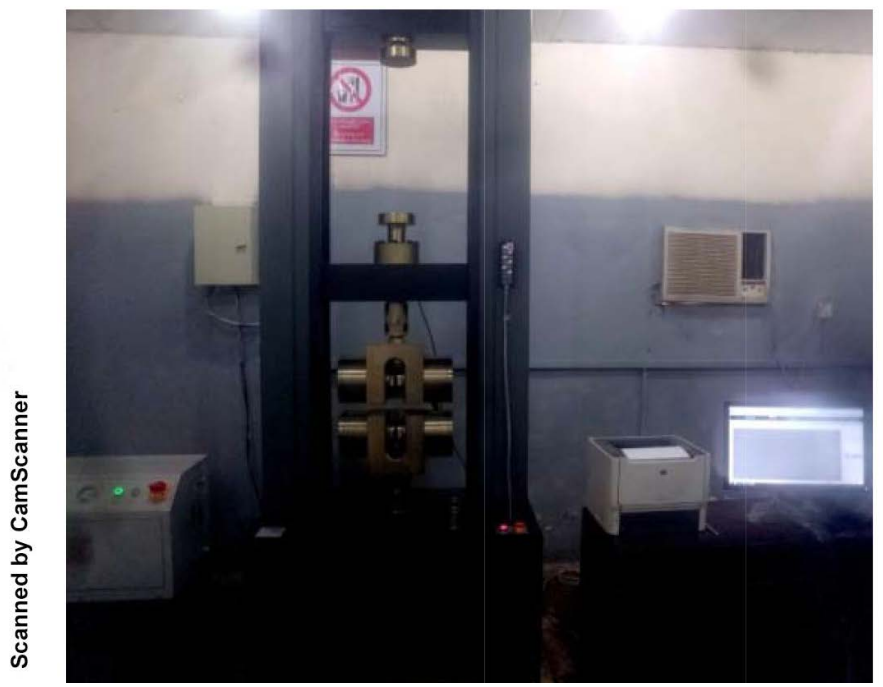

(d)

Figure 6. (a), BCCoral section for samples; (b), Dimension of tensile strength samples; (c) Tensile strength samples; (d) Tensile strength testing machine. 
a Metallographic microscope. The samples were ground, polished and tested according to ASTM B36/B36M-13 standard, which deals with C28000 or Muntz $60 \%$ brass. Graphs were captured in X100 magnification, illustrating alloy phases distributions accompanied with grain structure and sizes Figure 7.

\subsection{Chemical Composition Analysis}

Using chemical analyzer [ESAPORT ANALYTICAL INSTRUMENT-GNR], with two different brass programs (Brass alloy and High alloyed brass), chemical elements in the alloy were tested for the samples before and after firing Figure 8.

\section{Results}

Hardness test results were obtained according to the Table 1 and Table 2, the hardness of the fired brass case exhibits lower values from those in unfired case, namely (153 - 184) HB in unfired cases and (89 - 103) HB, in fired cases.

\subsection{Tensile Strength Results}

Results of tensile strength (TS) test are shown in Table 3, and graph in Figure 9.

Metallographic test results are represented by tow Metallographic images and tow tables. Figure 10(a), represents image for brass case structure before firing, and Figure 10(b) represents the structure after firing, the images reveal grains, grain contrast for copper and zinc, distribution and sizes of grains.

Table 4 \& Table 5 showed the grain size number, G, for brass before and after firing are 9.95 and 11.47, respectively. That means the grains before are bigger than after firing according to grain size and number rule $\left(\mathrm{N}=2^{\mathrm{G}-1}\right)[5]$.

\subsection{Chemical Composition Analysis Results}

Chemical composition analysis results are shown in Tables 6-8 and Figure 11 below. Firstly six samples were tested using two different brass analysis programs for comparison, which are, "Brass alloy program" and"High alloyed Brass
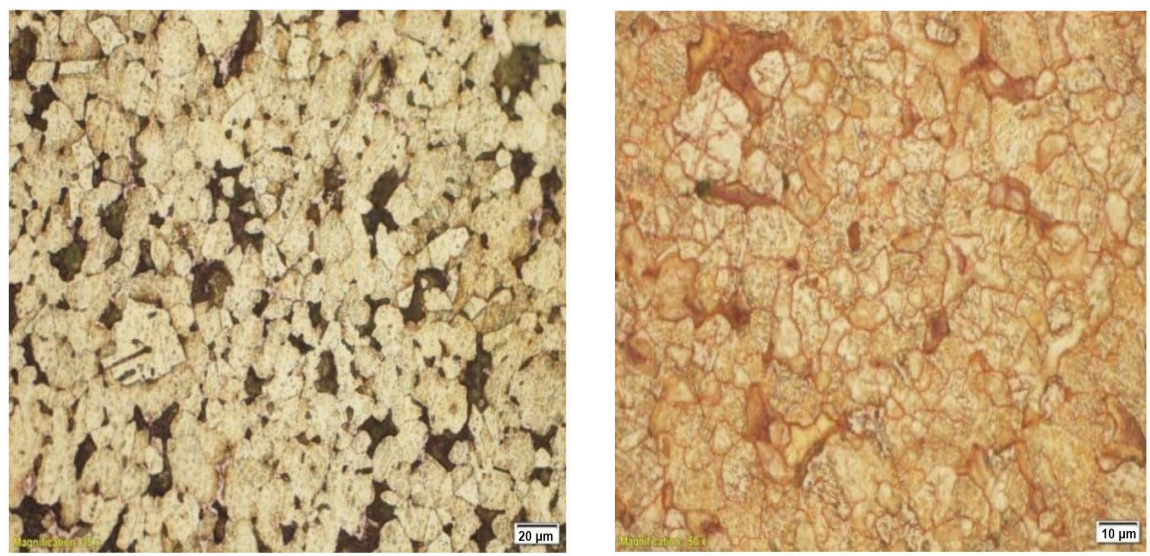

Figure 7. Structure before firing, left and after firing, right. 


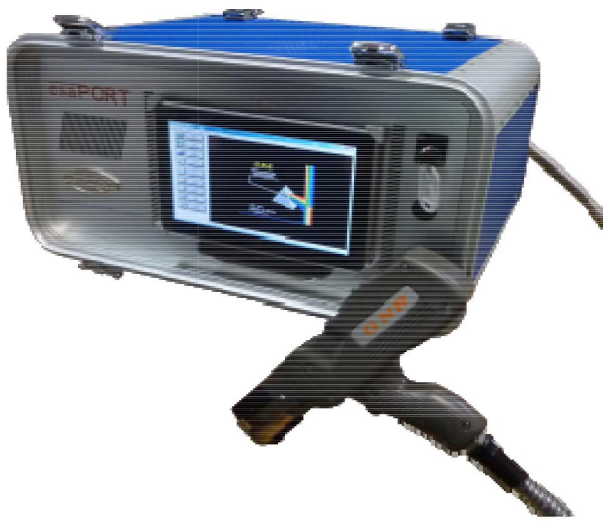

(a)

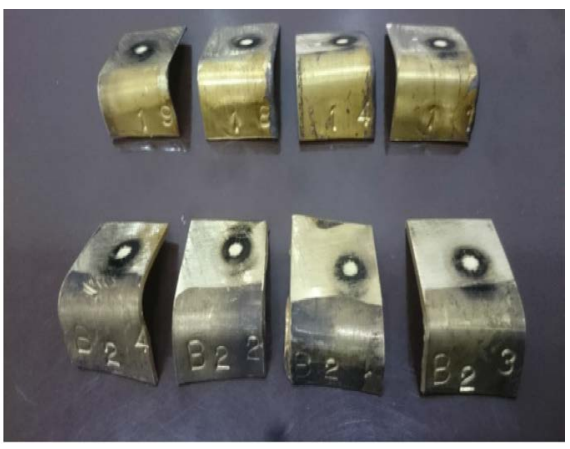

(a)

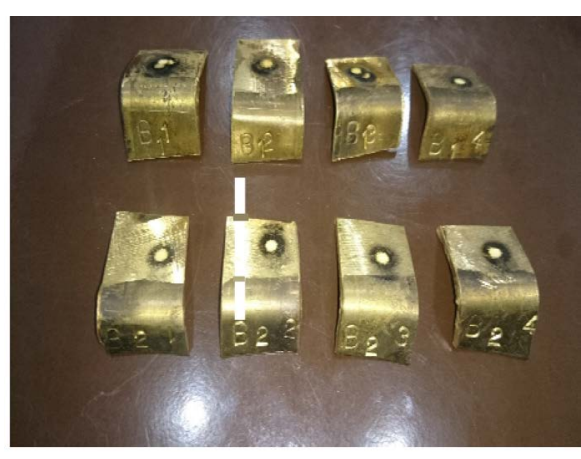

(b)

Figure 8 (a) Chemical analysis testing device (Esaport). (b) Chemical analysis test samples, before and after firing.

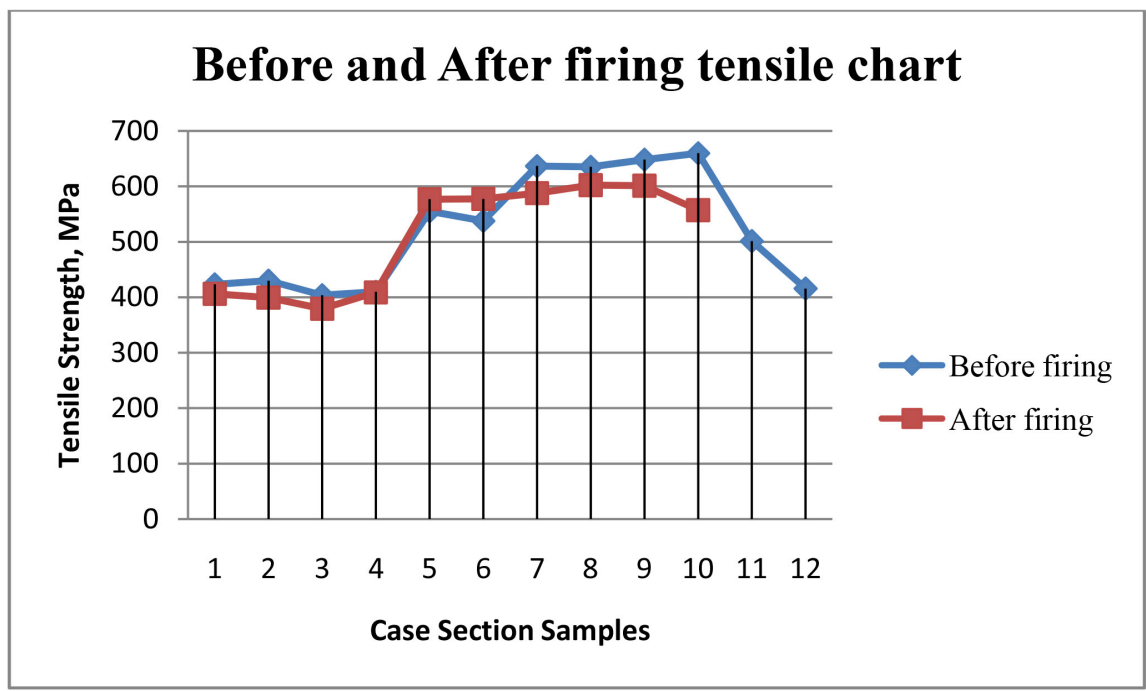

Figure 9. Tensile strength chart for samples before and after firing.

program". In both programs the results showed a notable decrease in the zinc percentage in the brass case after firing, Table 6 and Table 7; and Figure 11, although the "brass alloy program" is not accurate to reflect the actual zinc content in the alloy (36\% - 39\%). 


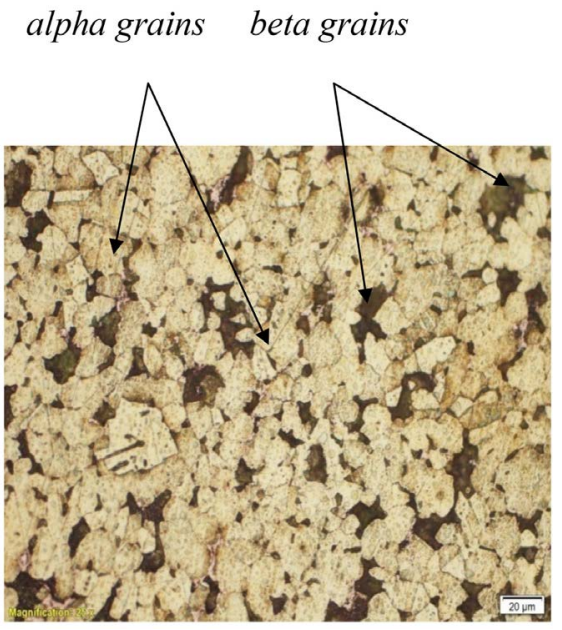

(a) zinc corrodes and leave porous residue

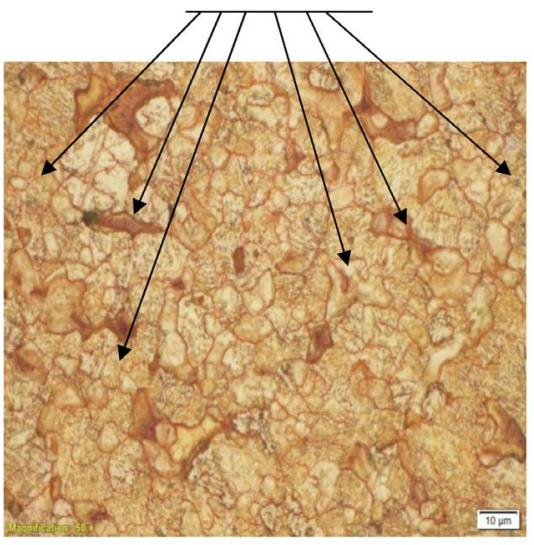

(b)

Figure 10. (a), Structure before firing alpha phase light \& beta phase dark, and (b), Structure after firing beta phase lighter \& decreased.

Table 1. Hardness obtained from testing unfired cartridge case samples.

\begin{tabular}{|c|c|c|c|c|c|}
\hline \multirow{2}{*}{ Sides } & \multirow{2}{*}{ Test samples } & \multicolumn{2}{|c|}{ Indentation diameter } & \multirow{2}{*}{$\begin{array}{c}\text { Average } \\
\text { d }\end{array}$} & \multirow{2}{*}{$\begin{array}{c}\text { Measured } \\
\text { HB }\end{array}$} \\
\hline & & $d_{1}$ & $d_{2}$ & & \\
\hline \multirow{6}{*}{ Inner surface } & 1 & 1.13 & 1.125 & 1.127 & 177 \\
\hline & 2 & 1.13 & 1.13 & 1.13 & 176 \\
\hline & 3 & 1.14 & 1.13 & 1.135 & 178 \\
\hline & 4 & 1.19 & 1.19 & 1.19 & 158 \\
\hline & 5 & 1.10 & 1.10 & 1.10 & 187 \\
\hline & 6 & 1.21 & 1.21 & 1.21 & 153 \\
\hline \multirow{6}{*}{ Outer surface } & 1 & 1.13 & 1.134 & 1.132 & 175 \\
\hline & 2 & 1.133 & 1.13 & 1.132 & 175 \\
\hline & 3 & 1.13 & 1.13 & 1.13 & 176 \\
\hline & 4 & 1.18 & 1.175 & 1.178 & 161 \\
\hline & 5 & 1.11 & 1.12 & 1.115 & 184 \\
\hline & 6 & 1.13 & 1.13 & 1.13 & 176 \\
\hline
\end{tabular}

Table 2. Hardness obtained from testing fired cartridge case samples.

\begin{tabular}{|c|c|c|c|c|c|}
\hline \multirow{2}{*}{ Sides } & \multirow{2}{*}{ Test indentation } & \multicolumn{2}{|c|}{ Indentation diameter } & \multirow{2}{*}{ Average } & \multirow{2}{*}{ Measured HB } \\
\hline & & $\mathrm{d} 1$ & $\mathrm{~d} 2$ & & \\
\hline \multirow{6}{*}{ Outer surface } & 1 & 1.55 & 1.552 & 1.55 & 89 \\
\hline & 2 & 1.448 & 1.45 & 1.45 & 103 \\
\hline & 3 & 1.55 & 1.55 & 1.55 & 89 \\
\hline & 4 & 1.4 & 1.4 & 1.4 & 111 \\
\hline & 5 & 1.4 & 1.43 & 1.415 & 110 \\
\hline & 6 & 1.4 & 1.4 & 1.4 & 111 \\
\hline \multirow{6}{*}{ Inner surface } & 1 & 1.55 & 1.45 & 1.5 & 95.5 \\
\hline & 2 & 1.45 & 1.447 & 1.449 & 103 \\
\hline & 3 & 1.44 & 1.45 & 1.445 & 101 \\
\hline & 4 & 1.45 & 1.45 & 1.45 & 103 \\
\hline & 5 & 1.46 & 1.45 & 1.455 & 102 \\
\hline & 6 & 1.45 & 1.47 & 1.46 & 102 \\
\hline
\end{tabular}


Table 3. Tensile strength for samples before and after firing in MPa.

\begin{tabular}{ccc}
\hline \multirow{2}{*}{ No. } & \multicolumn{2}{c}{ Before \& After firing TS } \\
\cline { 2 - 3 } 1 & Before firing TS & After firing TS \\
2 & 423.3 & 406.2 \\
3 & 429.9 & 399.47 \\
4 & 403.8 & 379.31 \\
5 & 409.8 & 408.81 \\
6 & 555.2 & 576.92 \\
7 & 537.6 & 577.39 \\
8 & 636.7 & 587.9 \\
9 & 635.2 & 602.36 \\
10 & 648.2 & 601.34 \\
11 & 659.8 & 557.09 \\
12 & 501.3 & \\
\hline
\end{tabular}

Table 4. Grain size number, G, and number of grains before firing.

\begin{tabular}{cc}
\hline A & B \\
Reference & A1 \\
Group & \\
Sample Comment & \\
Date & $1 / 19 / 20172: 36: 08$ PM \\
Standard & ASTM E 112-12 \\
ASTM Grain Size Number $G$ & 9.95 \\
Mean Grain Area $\left[\mu \mathrm{m}^{2}\right]$ & 130.5 \\
Total Number of Grains & 349 \\
Total Grain Area $\left[\mu \mathrm{m}^{2}\right]$ & $45,545.5$ \\
Analyzed Area $\left[\mu \mathrm{m}^{2}\right]$ & $59,473.92$ \\
Elongation & 0.95 \\
Image Number & ASTM Grain Size Number G
\end{tabular}

Table 5. Grain size number, $G$, and number of grains after firing.

\begin{tabular}{cc}
\hline A & B \\
Reference & A12-G \\
Group & \\
Sample Comment & \\
Date & $1 / 22 / 2017$ 10:46:40 AM \\
Standard & ASTM E 112-12 \\
ASTM Grain Size Number G & 11.47 \\
Mean Grain Area $\left[\mu \mathrm{m}^{2}\right]$ & 45.35 \\
Total Number of Grains & 1141 \\
Total Grain Area $\left[\mu \mathrm{m}^{2}\right]$ & $51,742.16$ \\
Analyzed Area $\left[\mu \mathrm{m}^{2}\right]$ & $59,473.92$ \\
Elongation & 0.99 \\
Image Number & ASTM Grain Size Number G \\
\hline
\end{tabular}


Table 6. Brass alloy program.

\begin{tabular}{cccc}
\hline & \multicolumn{3}{c}{ Samples } \\
\hline Zin\% in case before firing (group 1) & A1.1 & A1.2 & A1.3 \\
& 32.907 & 30.768 & $\mathbf{3 1 . 8 3 7}$ \\
Zin\% in case after firing (group 2) & A2.1 & A2.2 & A2.3 \\
& 32.04 & 30.67 & 31.355 \\
\hline
\end{tabular}

Table 7. High alloyed Brass program.

\begin{tabular}{cccc}
\hline & \multicolumn{3}{c}{ Samples } \\
\hline Zin\% in case before firing (group 1) & A1.1 & A1.2 & A1.3 \\
& 38.029 & 36.934 & 37.481 \\
Zin\% in case after firing (group 2) & A2.1 & A2.2 & A2.3 \\
& 37.777 & 36.619 & 37.198 \\
\hline
\end{tabular}

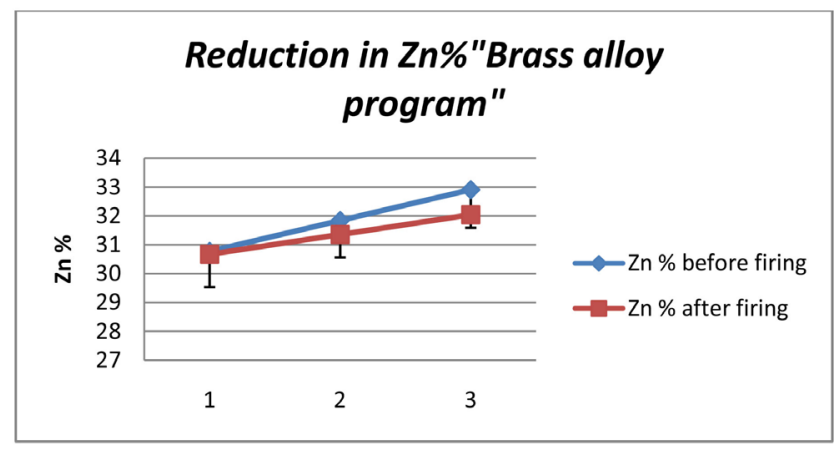

(a)

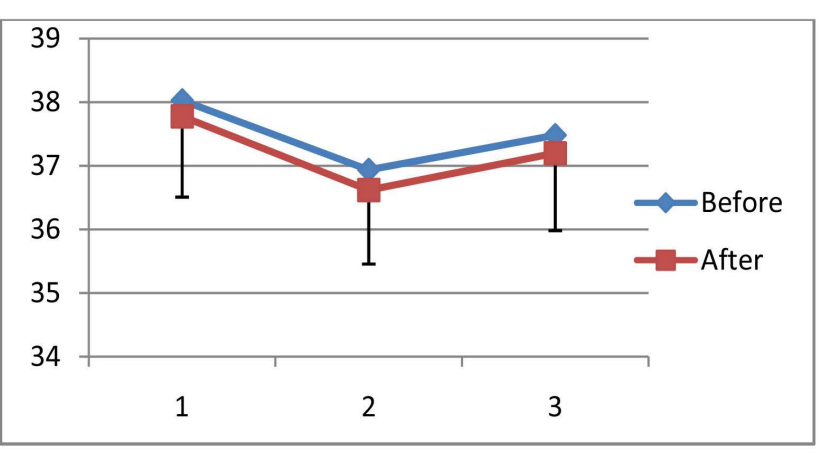

(b)

Figure 11. (a) Reduction in Z\% by "brass alloy program"; (b) Reduction in Z\% by "brass high alloy program".

Finally the "High alloyed Brass program" was adopted and demonstrated reduction in zinc after firing by $1 \%$ of that before firing. Table 8 and Figure 12 illustrates this result.

\section{Discussion}

It was seen from the results above, after firing brass cartridge case, there were indications to a reduction in the hardness and the tensile strength accompanied by microstructural disorder and chemical composition change.

According to Table $1 \&$ Table 2 the hardness ranged from (187 to153) HB with an average of 173.3 for unfired decreased to a range from (111 to 95.5) HB with an average of 102 in unfired cases, which is about $40 \%$ and the brass became softer. Since hardness is proportional to tensile strength, the results of tensile strength test showed this in Table 3 and Figure 9. The strength decreased from an average of 521.38 to $509.68 \mathrm{Mpa}$. about $2 \%$. Tensile strength chart in Figure 9, illustrates this reduction especially in the oral and root section of the 


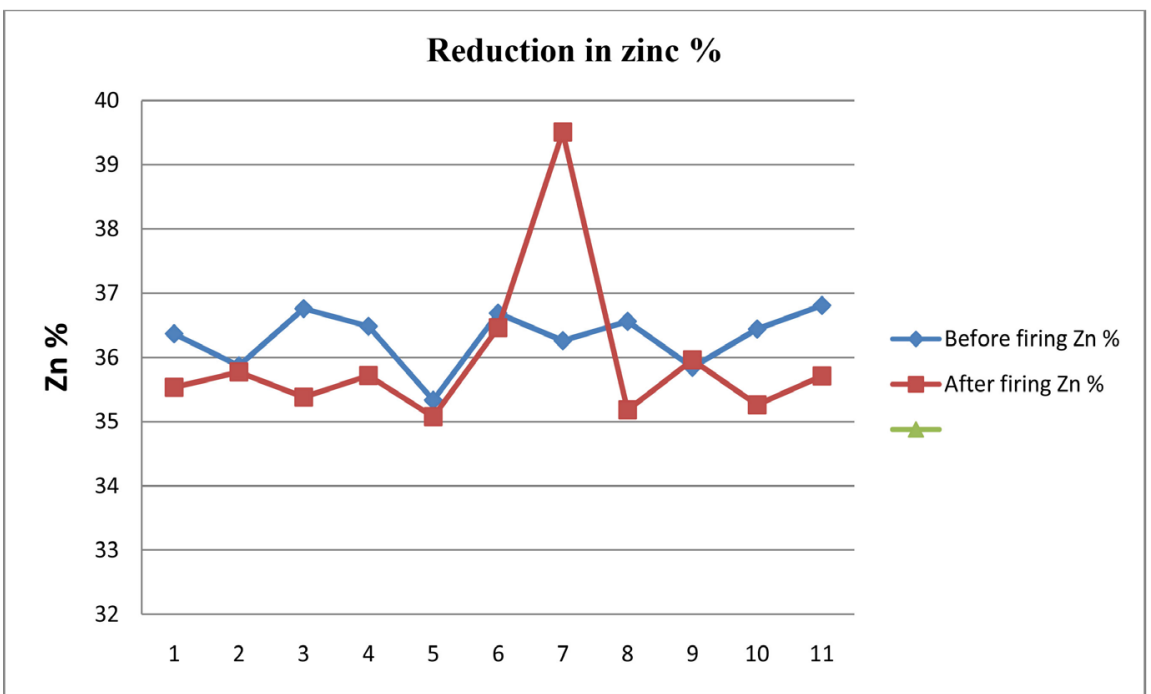

Figure 12. Reduction in Zn \% before and after firing "High alloyed Brass program".

Table 8. Chemical composition test for fired and unfired cartridge case.

\begin{tabular}{ccc}
\hline No. & Before firing $\mathrm{Zn} \%$ & After firing $\mathrm{Zn} \%$ \\
\hline 1 & 36.369 & 35.535 \\
2 & 35.87 & 35.773 \\
3 & 36.761 & 35.382 \\
4 & 36.486 & 35.719 \\
5 & 35.334 & 35.076 \\
6 & 36.689 & 36.465 \\
7 & 36.261 & 39.512 \\
8 & 36.562 & 35.182 \\
9 & 35.847 & 35.962 \\
10 & 36.442 & 35.262 \\
11 & 36.810 & 35.712 \\
\hline
\end{tabular}

case which is below the values of unfired case, as shown in Table 9 and Figure 13 by the red color.

In addition to the change of mechanical properties in brass, there was corresponding behavior in the microstructural properties which was revealed in the images Figure 10(a), Figure 10(b), and Table $4 \&$ Table 5. The grains became smaller in size after firing, that is from grain number, G, 9.95 to 11.47 respectively (according to grain size and number rule $\left(\mathrm{N}=2^{\mathrm{G}-1}\right)$ [5], the smaller the $\mathrm{G}$ the bigger the grain size and vice versa.).

According to the fact that, softening brass by annealing, grains grow and become bigger; while in this study result the grains became smaller and this may be as a response to the unusual effect of high pressure and temperature of firing.

Also the images (a) \& (b) Figure 14 reveals disorder of alpha and beta phases 
Table 9. Before and after firing tensile strength (TS).

\begin{tabular}{ccc}
\hline \multirow{2}{*}{ No. } & \multicolumn{2}{c}{ Before \& After firing TS } \\
\cline { 2 - 3 } & unfired case TS & After firing $T S$ \\
\hline 1 & 423.3 & 406.2 \\
3 & 429.9 & 399.47 \\
4 & 403.8 & 379.31 \\
& 409.8 & 408.81 \\
\hline
\end{tabular}

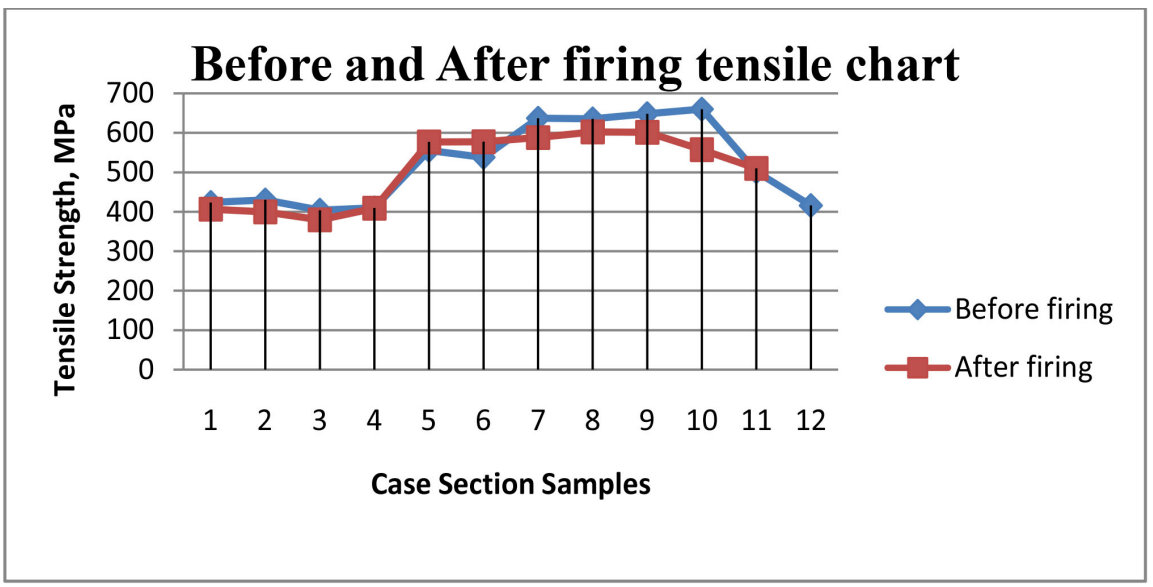

Figure 13. Tensile strength chart for samples before and after firing.

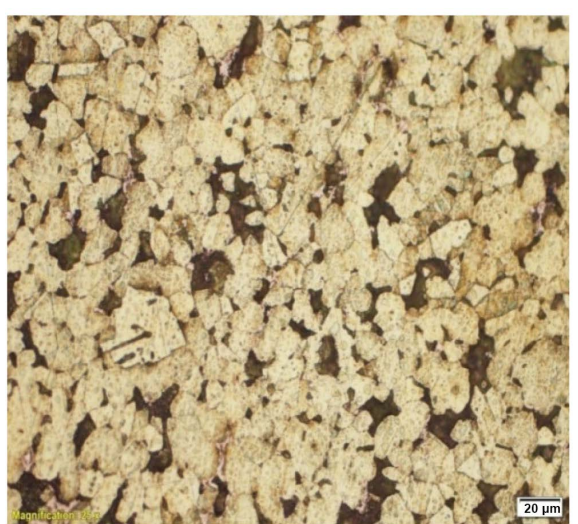

(a)

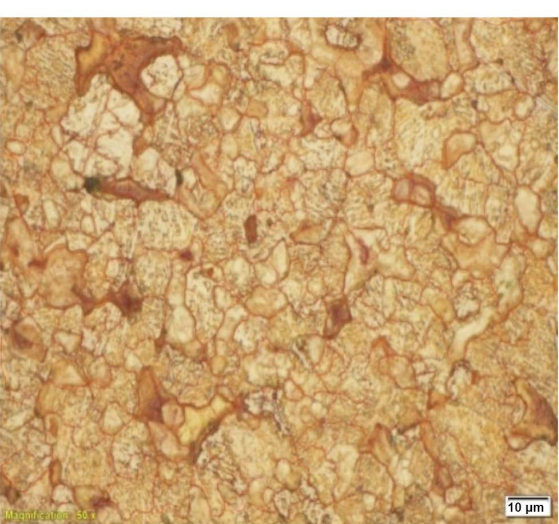

(b)

Figure 14. (a) microstructure before firing; (b) microstructure after firing.

where there is a reduction in the beta phase grains. Part of beta phase has been redistributed in the grain boundaries, Figure 14(a), with the remaining part of the phase less than that in the unfired image. In this situation the alpha phase dominate the structure and the properties of the brass which yield less hardness and strength.

The results from chemical composition showed the deficiency of zinc in the brass after firing as shown in Tables 6-8 and Figure 11(a), Figure 11(b) and Figure 12. Beta phase is mainly composed of zinc element and it is responsible 
for hardening and strengthening the brass alloy.

According to these findings the structure of the brass case has been remarkably changed after firing in terms of zinc deficiency in the alloy and insertion of beta phase in the grain boundaries. This can be attributed to the mechanism of imposing high temperature and pressure in a very short time of firing. further changes has been encountered in the mechanical performance namely the tensile strength which recorded less values than that of unfired cartridge and this affects any further use of the case.

Former studies justified prohibition of reloading BCC, by presence of cracks due to internal stresses situation described by Dr. Jeno Sipos [1], and the deformation exist after firing which was cured by cutting and replacing with semi combustible cartridge case found by R.K. Syal and P. S. Narr [2].

This study found another reason affecting reloading the brass cartridge case which was analyzed and attributed by the disruption occurred in the structure as described in the above sections.

\section{Summary and Conclusions}

After firing brass cartridge case, mechanical performance deteriorates which was observed from the test results. The strength decreased after firing by $2 \%$, which limits the reloading. It was due to the distortion occurred in the microstructure of the brass. And this was attributed to the zinc deficiency after firing. The reduction in $\mathrm{Zn} \%$ was about $1 \%$, between before and after firing samples, (36.31191 and 35.96182) in average.

This deficiency may be attributed to some sort of dezincification happening to brass influenced by the firing conditions. To reload the BCC, strength and structure should be treated and recovered.

\section{Acknowledgements}

Deep appreciation and special thanks to Professor Abdulfatah Bilal, Karary university supervisor of this research, for his real guidance, support and mentoring. This work was supported by Material research centre engineers, Ammar and Mihyar, and Giad group engineers, technicians and colleagues as I have managed my research experimental works and advices.

\section{Conflicts of Interest}

The author declares no conflicts of interest regarding the publication of this paper.

\section{References}

[1] Konečná, R. and Fintová, S. (2012) Copper and Copper Alloys. University of Žilina, Slovak Republic.

[2] Sipos, J. Crack Detection of Brass Artillery Cartridge Cases.

[3] Syal, R.K. and Narr, P.S. (1992) Cook-Off Study of Combustible Cartridge Cases. 
Defense Science Journal, 42, 373-381. https://doi.org/10.14429/dsj.42.4361

[4] Syal, R.K. and Narr, P.S. (1997) Study of Brass Obturator Design for Combustible Cartridge Case for $105 \mathrm{~mm}$ Tank Gun Ammunition. Defense Science Journal, 47, 373-381. https://doi.org/10.14429/dsj.47.4019

[5] ASTM E112-12, Standard Test Method for Determining Grain Size. 


\section{Nomenclature}

BCC: Brass Cartridge Case

CCC: Combustible Cartridge Case

HB: Brinell Hardness

TS: Tensile Strength

G: Grain size number

$\mathrm{N}$ : Total Surface area of grains 